\title{
Saliva and Serum Ghrelin and Obestatin in Iron Deficiency Anemia Patients
}

\author{
Kader Ugur 1,*, Suleyman Aydin ${ }^{2}$, Emir Donder ${ }^{3}$, İbrahim Sahin ${ }^{2,4}$, Meltem Yardim ${ }^{2}$, \\ Mehmet Kalayci ${ }^{2}$, Nevzat Gozel ${ }^{3}$, Ramazan Ulu ${ }^{5}$, Muhammed Sait Dag ${ }^{6}$, Murat \\ Sarikaya $^{7}$ \\ 1 Department of Endocrinology and Metabolism Disease, Firat University School of Medicine, Elazig 23119, \\ Turkey; kaderaksoy06@hotmail.com (K.U.) \\ 2 Department of Medical Biochemistry and Clinical Biochemistry (Firat Hormones Research group); Firat \\ University Hospital, Elazig 23119, Turkey; saydin1@hotmail.com (S.A.); ibrahimsahin@erzincan.edu.tr \\ (I.S.); meltem_yardim@hotmail.com (M.Y.);dr_mehmetkalayci@msn.com (M.K.) \\ 3 Department of Internal Medicine, Firat University Hospital, Elazig 23119, Turkey; e.donder33@hotmail.com \\ (E.D.); drngozel@hotmail.com (N.G.) \\ 4 Department of Medical Biology, School of Medicine, Erzincan Binali Yildirim University, Erzincan 24100, \\ Turkey; Ibrahimsahin@erzincan.edu.tr (İ.S.) \\ 5 Department of Nephrology, Firat University Hospital, Elazig 23119, Turkey; hekimulu@gmail.com (R.U.) \\ 6 Department of Gastroenterology, Medical Park Hospital, Gaziantep 27584, Turkey; \\ drmsait@windowslive.com (M.S.D.) \\ 7 Department of Gastroenterology, School of Medicine, Gaziosmanpaşa University, Tokat, Turkey; \\ dr.dangerous@hotmail.com (M.S.) \\ * Correspondence: kaderaksoy06@hotmail.com; Tel.: +90-5324402991
}

Abstract: Ghrelin and obestatin, two antagonist peptide hormones, are purportedly involved in stimulating appetite and controlling energy balance in humans. Serum ghrelin level is also associated with iron deficiency anemia (IDA), but no study has yet been made of the obestatin level in patients with IDA, even though both hormones are a single gene product. Therefore, the purpose of this investigation is to see whether there is a link between IDA and these two hormones among other hematological parameters in patients with IDA. To measure ghrelin and obestatin, human saliva and serum were collected from 30 women with IDA, aged $31.7 \pm$ 10.7 years, and 30 control women, aged $30.2 \pm 8.0$ years, with repeated collection of samples over a period of 1 week and 1 month. Saliva and serum ghrelin levels were measured by ELISA. Serum hemoglobin, ferritin, hematocrit and total iron-binding capacity (TIBC) values were determined with an Olympus AU2700. Saliva and serum ghrelin and obestatin levels were significantly lower in the IDA group compared with controls; these levels increased slightly above baseline with iron treatment, but remained below the control values. Furthermore, and as expected, serum hemoglobin, ferritin, and hematocrit levels were 
significantly increased with iron treatment, while total iron-binding capacity decreased compared to baseline concentrations. The findings suggest that IDA might be linked to imbalance of circulating (serum) and non-circulating (saliva) ghrelin and obestatin levels. Decreased ghrelin and obestatin might destroy iron homeostasis through its effect on intestinal absorption. Measuring these hormone levels might be useful for monitoring the response to iron treatment. Also, serum and saliva levels for both hormones were well correlated. Thus, using saliva in place of serum for monitoring the two hormones should minimize inconvenience and patient discomfort.

Keywords: iron deficiency anemia; obestatin; ghrelin

\section{Introduction}

Iron deficiency anemia (IDA), also known as sideropenic anemia, is one of the most common diseases of infancy and adults [1]. It is associated with a reduced quality of life $[1,2]$. This disease occurs when insufficient intake iron-containing foods or absorption of iron is insufficient or chronic bleeding and hemoglobin, which bears iron, cannot be formed. The cost of caring for a patient with IDA continues to grow with the increasing incidence of the diseases [1]. In the United States, between 2 and $5 \%$ of adolescent females have IDA, while developing countries [2] and in Turkey [3], IDA is much higher, with estimates of up to $10 \%$ of the populations. 1-2 mg of dietary iron intake is enough to maintain iron homeostasis [1]. A number of other studies, also exhibited hormonal alterations in subjects with IDA $[4,5]$. Further more recently, Isguven et al. [6] and Akarsu et al. [7] reported that total ghrelin decreased with IDA and concluded that appetite loss in iron deficiency is a result of decrement of appetite hormone ghrelin [6,7].

Ghrelin is a growth hormone secretagogue lipo-peptide hormone secreted from numerous human and mouse organs such as stomach [8], (reviewed [9]), kidney [10], teeth [11] and so. This hormone is composed of 28 amino-acids and is mainly found in two forms in biological fluids. One of its forms bears caprylic acid on the third amino-acid serine gat the N-terminal side, known acylated (active form) ghrelin. The other form was des-acylated, which has no bearing caprylic, and also known to be inactive form of this peptide hormone (reviewed [9]). Ghrelin levels have been extensively studied in various diseases such as preeclampsia [12], obesity (decreased [13-15]), cancer tissues (lost [10,16], decreased [10,16] or increased [17]), 
diabetes (decreased [18]), anorexia nervosa (increased [19]), hepatic and renal diseases (increased [20]). Besides other physiological functions, acylated ghrelin's well known effects are stimulate food intake and growth hormone secretion $[9,21]$. The other form of ghrelin (des-acylated ghrelin) is not totally active [21], since it causes cell proliferation.

Obestatin is another peptide hormone of endocrine system that is produced, like ghrelin, by cells lining the stomach [22], the small intestine, kidney, and salivary and mammary glands of humans (reviewed [9]). Both peptides are cleaved from preproghrelin. Obestatin was considered an antagonist of ghrelin [22]. However, several recent studies performed in rats and mice under various experimental conditions did not show antagonist of ghrelin results [23], (reviewed [24]). Further studies showed that obestatin was also involved in inhibiting thirst, improving memory, and affecting cell proliferation (reviewed [24]). As indicated above, ghrelin and obestatin might play crucial role or roles in a quite diverse range of physiologic functions in diseases, including IDA Since it has been shown that ghrelin decreased in children with IDA, it was concluded that loss of appetite was a result of decreased ghrelin [6,7]. However, both groups in those studies [6,7], they measured only total ghrelin in children with IDA and did not follow up by iron supplementation, whereas appetite stimulation could be achieved with acylated ghrelin [21]. Thus, it was necessary to measure acylated ghrelin rather than of total ghrelin if a relationship between ghrelin and appetite loss is to be found. Also, to the best of our knowledge, no one has investigated acylated ghrelin and obestatin secretetion, or their relationship to hematological parameters in adult females with IDA. In the present study, therefore, our goals were to assess acylated ghrelin and obestatin concentrations in adult females with IDA before and after iron supplementation. Association been both hormones and hematological parameters were also explored.

\section{Materials and Methods}

Informed consent was obtained from all volunteer participants after the approval (meeting number: 13, issue no.: 03 and dated 02.02.2016) of the local ethics committee School of Medicine of Firat University. The study included 30 female patients with IDA (mean age 31.7 \pm 10.7 years) who applied to the outpatient clinic of the Internal Medicine Department in the Frrat University Hospital, and 30 age- and sex-matched healthy individuals (mean age $30.2 \pm 8.0$ years). Patients' hemoglobin ( $\mathrm{Hb}$ ), hematocrit (Hct), red blood cell (RBC) count, mean corpuscular volume $(\mathrm{MCV})$, mean corpuscular hemoglobin $(\mathrm{MCH})$, mean corpuscular hemoglobin concentration (MCHC), serum iron and ferritin levels and total iron-binding 
capacity (TIBC) were measured. Low $\mathrm{Hb}$, hematocrit, red blood cell count, $\mathrm{MCV}, \mathrm{MCH}$, MCHC, serum iron, ferritin levels and high TIBC were taken as the criteria of an irondeficient patient. Patients with IDA orally treated with Ferroglycine sulfate $568 \mathrm{mg}$ (FerroSanol ${ }^{\circledR}$ duodenale capsule, Adeka) daily for 1month. For the control group, the following criteria were considered: age and body mass index (BMI) matched with the patients; no use of drugs, no diabetes or and family history of it, not taking alcohol, and no use of tobacco product (past or present); no gastrointestinal disease individually or in the family; no operation of the gastrointestinal system; no liver or kidney dysfunction, not walking more than $1 \mathrm{~km}$ a day; no history of obesity, no health complaints during the previous month; and, for women, being in the luteal phase. The patient group included subjects who met the control criteria, except for having an IDA. Venous blood $(8 \mathrm{~mL})$ and saliva $(1 \mathrm{~mL})$ samples were before treatment after fasting overnight, and also 1 week and 1month after drug treatment. Samples were collected once only from the control subjects. Saliva was taken into clean container containing $500 \mathrm{KIU} / \mathrm{mL}$ aprotinin, as previously described [25]. Each saliva samples was also treated with $1 / 10$ vol $1 \mathrm{~N} \mathrm{HCl}$ and stored at $-20^{\circ} \mathrm{C}$ pending measurements of ghrelin. Each blood sample was divided into 2; one half was put into tubes containing 500 $\mathrm{KIU} / \mathrm{mL}$ aprotinin, and the other half into untreated tubes. The tubes were centrifuged for 5 min at $4000 \mathrm{rpm}$ to separate the serum, which was treated with $1 / 10$ (vol/vol) $1 \mathrm{~N} \mathrm{HCl}$ and stored at $-20^{\circ} \mathrm{C}$ pending measurements of ghrelin and obestatin levels. Untreated tubes were used to analyze for the other biochemical parameters ( $\mathrm{Hb}$, Hct, ferritin, TIBC). Hb, Hct, ferritin, and TIBC levels were analyzed on the same day in an Olympus AU2700 auto analyzer using Olympus kits (Olympus Corp., Tokyo-Japan). Serum and saliva obestatin levels were determined by enzyme immunoassay (EIA,) in an ELISA reader (TRITURUS, Barcelona, Spain) using a kit (EIA, S-1285; Peninsula Laboratories LLC, CA, USA). Serum and saliva ghrelin levels were also measured by an enzyme-linked immunosorbent assay (ELISA) in an ELISA reader using a sensitive human ghrelin ELISA kit (SPI; Cat\# A05119, Montigny le Bretonneux, France).

\subsection{Statistical analysis}

SPSS 22.0 (SPSS Inc. Chicago, Illinois, USA) software was used for statistical comparisons of data. The Kolmogorov-Smirnov $\mathrm{Z}$ test showed that the data were not normally distributed. Therefore, the the Mann-Whitney test was employed for between-group comparisons. The Friedman test was used to compare ghrelin and obestatin concentrations at 
baseline and 1 week and 1 month later, with the level of significance set at $p<0.05$. The Wilcoxon test was used to compare the 2 groups. The data are expressed as mean \pm standard deviation (S.D.) and $\mathrm{p}$ values $<0.05$ were considered significant.

\section{Results}

The hematological findings and demographic characteristics of the healthy and IDA individuals are presented in Table I.

Table 1. The hematological findings and demographic characteristics of the healthy $(n=30)$ and IDA subjects

\begin{tabular}{cccc}
\multicolumn{3}{c}{$(\mathrm{n}=30)$} \\
\hline Parameters & Control $(\mathbf{n}=\mathbf{3 0})$ & Basal & PDA (n=30) \\
& & $23.51 \pm 5.82$ & $24.27 \pm 5.64$ \\
BMI $\left(\mathrm{Kg} / \mathrm{m}^{2}\right)$ & $24.12 \pm 4.80$ & $1.99 \pm 0.67$ & $37.13 \pm 29.28$ \\
Ferritin (ng/mL) & $92.25 \pm 8.56$ & $8.21 \pm 1.65$ & $11.98 \pm 1.54$ \\
$\mathrm{Hb}(\mathrm{gr} / \mathrm{dL})$ & $14.19 \pm 1.26$ & $28.93 \pm 4.51$ & $36.41 \pm 4.59$ \\
$\mathrm{Hct}(\%)$ & $42.50 \pm 2.56$ & $20.18 \pm 3.32$ & $24.25 \pm 2.73$ \\
$\mathrm{MCH}(\mathrm{pg})$ & $23.2 \pm 3.40$ & $28.62 \pm 2.27$ & $31.09 \pm 1.72$ \\
$\mathrm{MCHC}(\mathrm{gr} / \mathrm{dL})$ & $33.8 \pm 3.40$ & $67.25 \pm 5.85$ & $80.12 \pm 6.35$ \\
$\mathrm{MCV}(\mathrm{fL})$ & $87.30 \pm 6.40$ & $412000 \pm 85000$ & $325000 \pm 26000$ \\
$\mathrm{PLT}(\mathrm{K} / \mathrm{uL})$ & $242000 \pm 32000$ & $4.84 \pm 0.602$ & $5.17 \pm 0.61$ \\
$\mathrm{RBC}(\mathrm{M} / \mathrm{uL})$ & $4.8 \pm 0.40$ & $392.40 \pm 48.95$ & $258.51 \pm 102.25$ \\
$\mathrm{TIBC}(\mathrm{mcg} / \mathrm{dL})$ & $212.20 \pm 18.65$ & &
\end{tabular}

BMI: Body mass index; Hb: Hemoglobin; MCV: Mean corpuscular volume; fL: femtolitre; PLT: Platelets; $\mathrm{ng} / \mathrm{mL}=$ nanograms per milliliter; RBC: Red blood count; TIBC: Total iron-binding capacity; $\mathrm{mcg} / \mathrm{dL}=$ micrograms per deciliter.

Patient's $\mathrm{Hb}$, Hct, and ferritin levels were remarkably increased while total iron-binding capacity (TIBC) decreased when compared with the initial levels. Subjects's glucose values were $84.1 \pm 3.20 \mathrm{mg} / \mathrm{dL}$ (controls); $91.44 \pm 12.20 \mathrm{mg} / \mathrm{dL}$ (before treatment); $87.07 \pm 7.90 \mathrm{mg} / \mathrm{dl}$ (after treatment). Subjects's BMI were 24.12 \pm 4.80 (controls); $23.51 \pm 5.82$ (before treatment); $24.27 \pm 5.64$ (after treatment). When weight after treatment was compared, an increase was seen in the BMI of patients compared with their weight at the start, but again this was not statistically significant. Saliva and serum ghrelin and obestatin levels were measured at the start, after 1 week and 1 month later. Serum and saliva ghrelin and obestatin levels were significantly lower than control values $(p<0.001)$ (Figure 1, 2, 3, and 4). Serum ghrelin and obestatin concentrations increased with iron treatment when compared with the intial values, but this increment was not statistically significant (Figure 2, and 4). Even though patients 
gained some weight, ghrelin tended to be increased, but once again this increment was not statistically significant. While it is known that ghrelin levels reduce obesity $[13,15]$, an exception is the Prader Willi syndrome where increased ghrelin levels seem to be involved in the development of an obese phenotype [26]. Saliva ghrelin and obestatin were increased with treatment when compared with the control (basal) values, but this increase was not statistically significant (Figure 1, and 3).

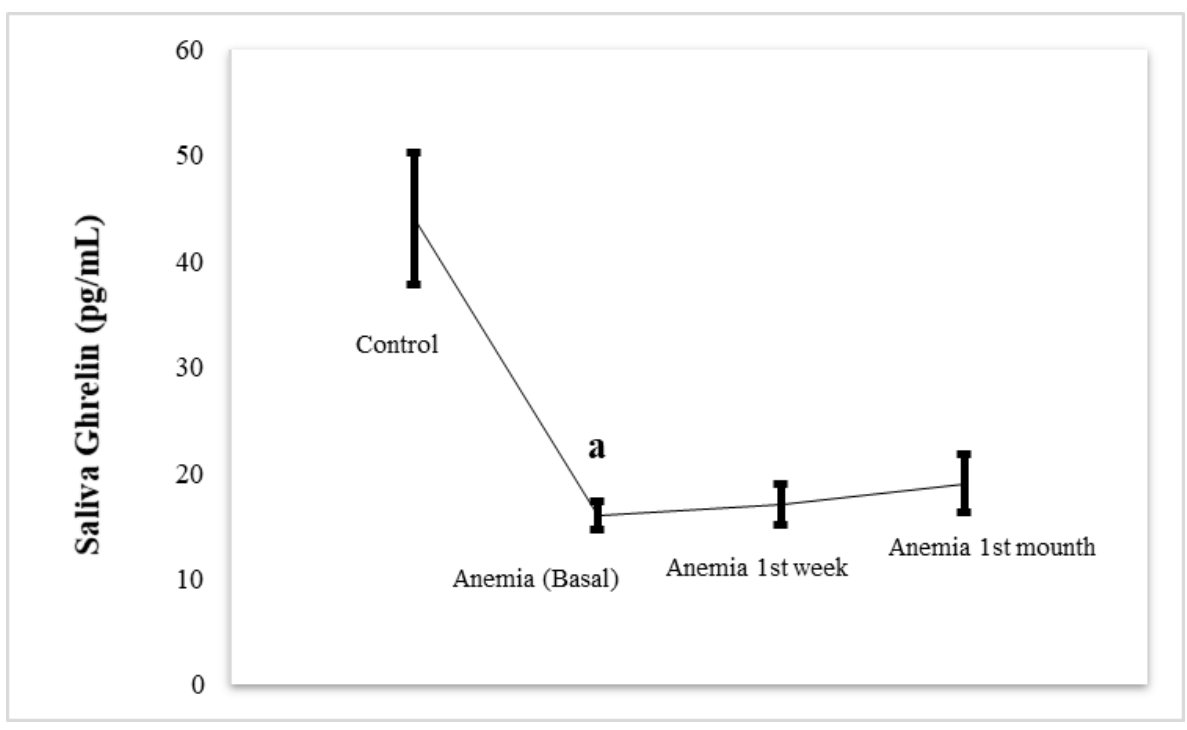

Figure 1. Saliva ghrelin levels before treatment and after treatment. Values are mean $\pm S D$. $p<0.05$ vs corresponding control vs. before and after treatment.

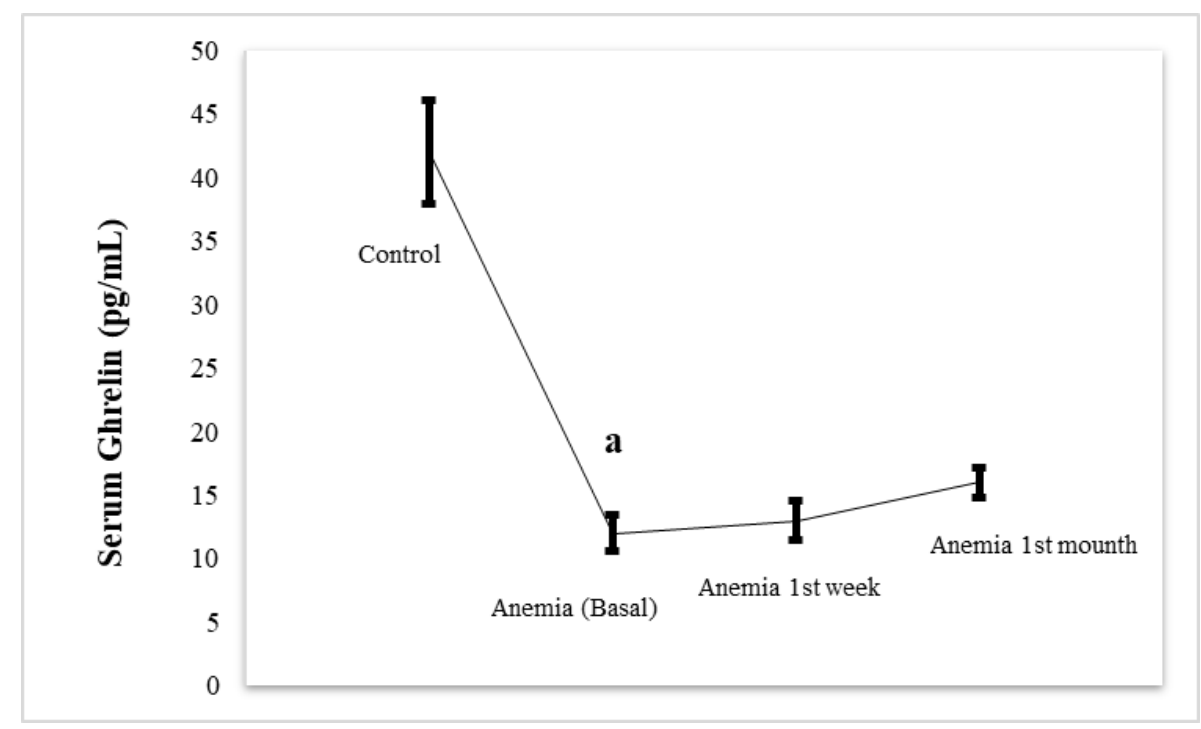

Figure 2. Serum ghrelin levels before treatment and after treatment. Values are mean $\pm \mathrm{SD}$. $\mathrm{p}<0.05$ vs corresponding control vs. before and after treatment. 


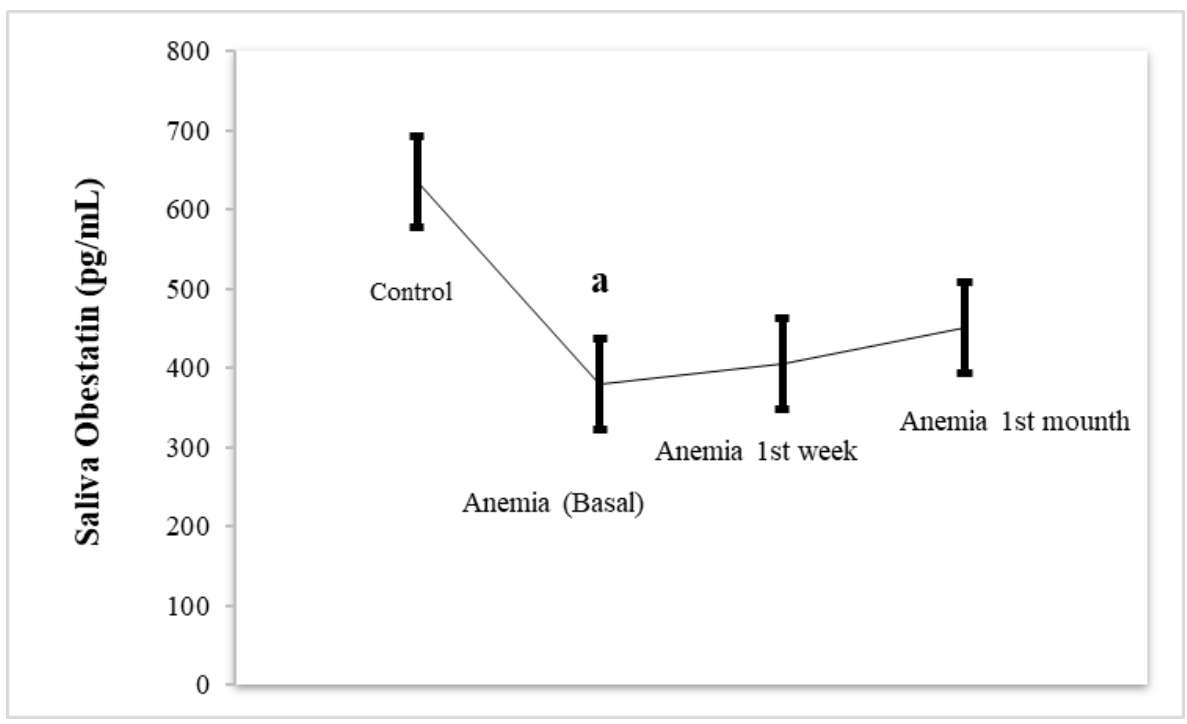

Figure 3. Saliva obestatin levels before treatment and after treatment. Values are mean \pm SD. $p<0.05$ vs corresponding control vs. before and after treatment.

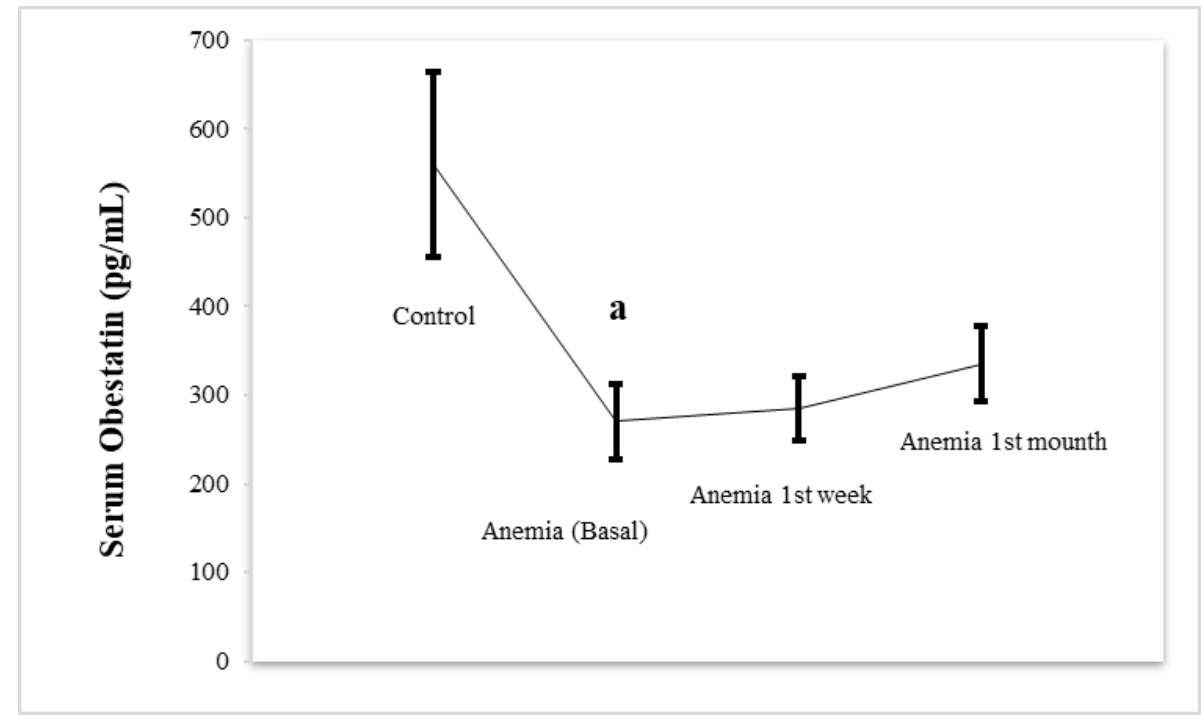

Figure 4. Serum obestatin levels before treatment and after treatment. Values are mean \pm SD. $p<0.05$ vs corresponding control vs. before and after treatment.

\section{Discussion}

Iron is a necessary element for all cells, and plays an important role in energy metabolism, gene regulation, neurotransmitter synthesis, cell growth and differentiation, cofactor of enzymic reactions (e.g. dehydratases), protein synthesis, oxygen binding and transport (hemoglobin and myoglobin) [1,27,28]. Its absorption occurs primarily in the 
duodenum and is then used for hemoglobin synthesis, mitochondrial enzymes and cytochromes-heme containing proteins that promote oxidative phosphorylation within the mitochondria. Hemoglobin in red blood cells carries oxygen to the tissues from the lungs. But if iron levels are too low, the number of red blood cells and hemoglobin production falls below normal, resulting in IDA [1]. This anemia is also associated with some bioactive peptide hormonal changes [4,7]. In this study, both saliva and serum basal hormone acylated ghrelin concentrations in subjects with IDA were significantly lower levels when compared with the control group without IDA. After iron supplementation, ghrelin concentration tended to be increased compared with their basal ghrelin concentrations. These results agree with the findings of İsguven et al. [6] and with Akarsu et al., [7] who previously noted that total ghrelin was decreased in children with IDA. Like them, we also assumed that loss of appetite correlated with a decreased level of ghrelin in adult females with IDA. But we measured acylated ghrelin rather than total ghrelin amount they had measured. While appetite stimulation in organisms is due to acylated ghrelin, it is more important to distinguish acylated ghrelin from total ghrelin before making the above assumption [21], (reviewed [9]).

We also observed that serum glucose concentrations were slightly higher in patients with IDA than controls. Iron absorption is increased by the presence of glucose, so that increased glucose in patient with IDA might be a compensatory mechanism that triggers increased iron absorption. Our glucose results are in agreement with Coban et al., who reported that, before iron treatment, the mean HbAlc level in patients with IDA was higher than in a healthy control group [29]. It is well known that when glucose increases, ghrelin decreases [18], making it possible that this ghrelin decrement with IDA might be a result of increased glucose increasement, and therefore gives another explanation why ghrelin decreases with IDA.

Ghrelin was originally recognized via its role in growth hormone releasing (hence its name), but it has become evident that it has many roles, including appetite stimulation, gastric motility and acid secretion [8]. Gastric acid secretion has been also demonstrated to facilitate iron absorption (reviewed [30]). Also, ghrelin significantly increased $\mathrm{H}(+)-\mathrm{K}(+)$-ATPase activity of gastric mucosal cells [31]. If this is so, decreased ghrelin may not increase gastric acid secretion. Hence the low iron level observed with IDA in our investigation might be a result of a low concentration of ghrelin. The low iron level might be a result of insufficient iron in the diet, along with impaired uptake by thegastrointestinal systems. We found that, ferritin level was increased with iron supplementation, as expected, even though ghrelin tended to increase with this supplementation; however, the increase was not statistically significant. Superoxide radicals can be generated from free iron-liberated ferritin, which then 
catalyse the production of further hydroxyl radical by increasing the amount of free iron [27]. A similar effect can occur with Fe-S proteins in SOD-deficiency, with the degradation of mitochondria by radical damage leading to further production of radicals and resulting oxidative stress [32]. This observation agrees with Day et al., who observed that chronic iron administration elevates vascular oxidative stress [27]. Here, ghrelin seems to be highly effective in protecting against reactive oxygen species (ROS) because of its antioxidant properties that upregulates free-radical scavenger [33], and one that appears to involve antiinflammatory activity [34]. Therefore, the low ghrelin (even after iron supplementation) might be consistent with the view that the body is attempting to deal with these problems by consuming ghrelin [33]. Hydroxyl radical, produced by the iron-catalyzed Haber-Weiss reaction, might also damage gastric mucosal cells [27,35]. This hormone is produced mainly by P/D1 cells lining the fundus of stomach (reviewed [33]). If, as assumed, gastric mucosal cells (the main producers of ghrelin) are damaged by ROS, this might reduce ghrelin secretion. However, further investigations will be necessary to determine whether there is a link between ROSs, Fe metabolism and ghrelin level.

We also observed that both saliva and serum obestatin were clearly lower in the IDA patients compared with the control subjects; and after iron supplementation, obestatin concentration tended to be increased, like ghrelin, even though serum obestatin showed fluctuations when compared with basal obestain level after one week (slightly decreased), and one month (slight increase). Serum obestatin and ghrelin are produced by many organs, including kidney and liver, although most is produced by P/D1 cells lining the fundus of human stomach and X/A cells of rats [8]. Serum obestatin could be lowered as a result of changes in synthesis in the stomach. This assumption is supported by decreased ghrelin a peptide derived from the same prohormone. Both hormones are encoded by the same gene [24], therefore parallel increases or decreases in ghrelin and obestatin can be expected, as reported here. In the case of obestatin, we have not found a similar study in IDA with which to compare our results.

Our investigation has the following limitations. First, the limiting factor was the small sample size and the restriction of the measurements to 1 month. A longer follow-up period would be useful to determine more accurately how hormonal levels change with iron treatment. Futhermore, total anti-oxidant capacity should be also measured in the patient with IDA because ghrelin shows antioxidant properties.

\section{Conclusions}


Briefly, we can conclude that ghrelin and obestatin can be analyzed in serum and saliva by using ELISA. Testing these hormones in saliva is simple and non-invasive. Serum monitoring in this disease could be replaced by measuring saliva level of these hormones. Ghrelin and obestatin might effect intestinal absorption of iron and mobilization from hepatic stores, where ghrelin and obestatin are also expressed. A significant decrease in ghrelin and obestatin is probably the consequence of fundus damage following iron treatment. For this reason, determination of ghrelin and obestatin concentrations may also reflect iron storage of the body, and might possibly be an indicator of damage to the stomach, as well as being an indicator of appetite loss in iron-deficient women. However, further research involving a larger prospective study is needed to elucidate the mechanisms leading to decreased serum ghrelin and obestatin in IDA.

Author Contributions: Conceived and designed the experiments: S.A., K.U., ED, N.G. Analyzed the data: IS, MY, MK, R.U. Wrote the first draft of the manuscript: KU, SA. Contributed to the writing of the manuscript: SD, MS. Agree with manuscript results and conclusions: S.A., K.U., ED, N.G. Jointly developed the structure and arguments for the paper: IS, MY, MK, R.U. Made critical revisions and approved final version: S.A., K.U., ED, N.G. All authors reviewed and approved of the final manuscript.

Conflicts of Interest: The authors have nothing to disclose that directly or indirectly might affect, or be perceived to affect, the conduct or reporting of the work they have submitted.

\section{References}

1. Goldman, Lee.; Schafer, I.A. Cecil Textbook of Medicine, 23rd ed.: Saunders Elsevier. Microcytic and hypochromic anemias 2008, 1187-1194.

2. O'Brien, K.O.; Ru, Y. Iron status of North American pregnant women: an update on longitudinal data and gaps in knowledge from the United States and Canada. Am. J. Clin. Nutr. 2017, 106, 1647S-1654S.

3. Okan, V.; Cigiloglu, A.; Cifci, S.; Yilmaz, M.; Pehlivan, M. Red cell indices and functions differentiating patients with the beta-thalassaemia trait from those with iron deficiency anaemia. J. Int. Med. Res. 2009, 37, 25-30.

4. Yapakçi, E.; Tarcan, A.; Celik, B.; Ozbek, N.; Gürakan, B. Serum pro-hepcidin levels in term and preterm newborns with sepsis. Pediatr. Int. 2009, 51, 289-292.

5. Stelle, I.; Kalea, A.Z.; Pereira, D.I.A. Iron deficiency anaemia: experiences and challenges. Proc. Nutr. Soc. 2018, 10, 1-8. Article in press.

6. Isguven, P.; Arslanoglu, I.; Erol, M.; Yildiz, M.; Adal, E.; Erguven, M. Serum levels of ghrelin, leptin, IGF-I, IGFBP-3, insulin, thyroid hormones and cortisol in prepubertal children with iron deficiency. Endocr. J. 2007, 54, 985-990.

7. Akarsu, S.; Ustundag, B.; Gurgoze, M.K.; Sen, Y.; Aygun, A.D. Plasma ghrelin levels in various stages of development of iron deficiency anemia. J. Pediatr. Hematol. Oncol. 2007, 29, 384-387.

8. Kojima, M.; Hosoda, H.; Date, Y.; Nakazato, M.; Matsuo, H.; Kangawa, K. Ghrelin is a growth-hormonereleasing acylated peptide from stomach. Nature 1999, 402, 656-660.

9. Aydin, S. Discovery of Ghrelin Hormone: Research and Clinical Applications. Turk J. Biochem. 2007, 32, 76-89.

10. Dagli, A.F.; Aydin, S.; Karaoglu, A.; Akpolat, N.; Ozercan, I.H.; Ozercan, M.R. Ghrelin expression in normal kidney tissue and renal carcinomas. Pathol. Res. Pract. 2009, 205, 165-173.

11. Aydin, S.; Ozercan, I.H.; Geckil, H.; Dagli, F.; Aydin, S.; Kumru, S.; Kilic, N.; Sahin, I.; Ozercan, M.R. Ghrelin is present in teeth. J. Biochem. Mol. Biol. 2007, 40, 368-372. 
12. Aydin, S.; Guzel, S.P.; Kumru, S.; Aydin, S.; Akin, O.; Kavak, E.; Sahin, I.; Bozkurt, M.; Halifeoglu, I. Serum leptin and ghrelin concentrations of maternal serum, arterial and venous cord blood in healthy and preeclamptic pregnant women. Physiol. Biochem. 2008, 64, 51-59.

13. Sahin, I.; Aydin, S.; Ozkan, Y.; Dagli, A.F.; Akin, K.O.; Guzel, S.P.; Catak, Z.; Ozercan, M.R. Diet-induced obesity suppresses ghrelin in rat gastrointestinal tract and serum. Mol. Cell Biochem. 2011, 355, 299-308.

14. Önnerfält, J.; Erlanson-Albertsson, C.; Montelius, C.; Thorngren-Jerneck, K. Obese children aged 4-6 displayed decreased fasting and postprandial ghrelin levels in response to a test meal. Acta Paediatr. 2018, 107, 523-528.

15. Aydin, S.; Sahin, I.; Ozkan, Y.; Dag, E.; Gunay, A.; Guzel, S.P.; Catak, Z.; Ozercan, M.R. Examination of the tissue ghrelin expression of rats with diet-induced obesity using radioimmunoassay and immunohistochemical methods. Mol. Cell Biochem. 2012, 365, 165-173.

16. Mottershead, M.; Karteris, E.; Barclay, J.Y.; Suortamo, S.; Newbold, M.; Randeva, H.; Nwokolo, C.U. Immunohistochemical and quantitative mRNA assessment of ghrelin expression in gastric and oesophageal adenocarcinoma. J. Clin. Pathol. 2007, 60, 405-409.

17. Komarowska, H.; Rucinski, M.; Tyczewska, M.; Sawicka-Gutaj, N.; Szyszka, M.; Hernik, A.; Klimont, A.; Milecka, P.; Migasiuk, L.; Biczysko, M.; et al. Ghrelin as a potential molecular marker of adrenal carcinogenesis: In vivo and in vitro evidence. Clin. Endocrinol. (Oxf). 2018, 89, 36-45.

18. Aydin, S. A comparison of ghrelin, glucose, alpha-amylase and protein levels in saliva from diabetics. $J$. Biochem. Mol. Biol. 2007, 40, 29-35.

19. Harada, T.; Nakahara, T.; Yasuhara, D.; Kojima, S.; Sagiyama, K.; Amitani, H.; Laviano, A.; Naruo, T.; Inui, A. Obestatin, acyl ghrelin, and des-acyl ghrelin responses to an oral glucose tolerance test in the restricting type of anorexia nervosa. Biol. Psychiatry. 2008, 63, 245-247.

20. Koch, A.; Sanson, E.; Helm, A.; Voigt, S.; Trautwein, C.; Tacke, F. Regulation and prognostic relevance of serum ghrelin concentrations in critical illness and sepsis. Crit. Care. 2010, 14, R94.

21. Rodríguez, A.; Gómez-Ambrosi, J.; Catalán, V.; Gil, M.J.; Becerril, S.; Sáinz, N.; Silva, C.; Salvador, J.; Colina, I.; Frühbeck, G. Acylated and desacyl ghrelin stimulate lipid accumulation in human visceral adipocytes. Int. J. Obes. (Lond). 2009, 33, 541-552.

22. Zhang, J.V.; Ren, P.G.; Avsian-Kretchmer, O.; Luo, C.W.; Rauch, R.; Klein, C.; Hsueh, A.J. Obestatin, a peptide encoded by the ghrelin gene, opposes ghrelin's effects on food intake. Science 2005, 310, 996-999.

23. De Smet, B.; Thijs, T.; Peeters, T.L.; Depoortere, I. Effect of peripheral obestatin on gastric emptying and intestinal contractility in rodents. Neurogastroenterol. Motil. 2007, 19, 211-217.

24. Ren, A.J.; Guo, Z.F.; Wang, Y.K.; Lin, L.; Zheng, X.; Yuan, W.J. Obestatin, obesity and diabetes. Peptides 2009, 30, 439-444.

25. Hosoda, H.; Doi, K.; Nagaya, N.; Okumura, H.; Nakagawa, E.; Enomoto, M.; Ono, F.; Kangawa, K. Optimum collection and storage conditions for ghrelin measurements: octanoyl modification of ghrelin is rapidly hydrolyzed to desacyl ghrelin in blood samples. Clin. Chem. 2004, 50, 1077-1080.

26. Feigerlová, E.; Diene, G.; Conte-Auriol, F.; Molinas, C.; Gennero, I.; Salles, J.P.; Arnaud ,C.; Tauber, M. Hyperghrelinemia precedes obesity in Prader-Willi syndrome. J. Clin. Endocrinol. Metab. 2008, 93, 28002805.

27. Day, S.M.; Duquaine, D.; Mundada, L.V.; Menon, R.G.; Khan, B.V.; Rajagopalan, S.; Fay, W.P. Chronic iron administration increases vascular oxidative stress and accelerates arterial thrombosis. Circulation 2003, 107, 2601-2606.

28. Bae, D.H.; Lane, D.J.R.; Jansson, P.J.; Richardson, D.R. The old and new biochemistry of polyamines. Biochim. Biophys. Acta. 2018, Article in press.

29. Coban, E.; Ozdogan, M.; Timuragaoglu, A. Effect of iron deficiency anemia on the levels of hemoglobin A1c in nondiabetic patients. Acta Haematol, 2004, 112, 126-128.

30. Schubert, M.L. Gastric secretion. Curr. Opin. Gastroentero. 2007, 23, 595-601.

31. Du, G.M.; Shi, Z.M.; Wei, X.H.; Liu, M.J.; Zhang, L.; Zhao, R.Q. Expression of gastric ghrelin and H(+)$\mathrm{K}(+)$-ATPase mRNA in weanling piglets and effect of ghrelin on $\mathrm{H}(+)-\mathrm{K}(+)$-ATPase expression and activity in gastric mucosal cells in vitro. Res. Vet. Sci. 2007, 82, 99-104.

32. Valko, M.; Rhodes, C.J.; Moncol, J.; Izakovic, M.; Mazur, M. Free radicals, metals and antioxidants in oxidative stress-induced cancer. Chem. Biol. Interact. 2006, 160, 1-40.

33. El Eter, E.; Al Tuwaijiri, A.; Hagar, H.; Arafa, M. In vivo and in vitro antioxidant activity of ghrelin: Attenuation of gastric ischemic injury in the rat. J. Gastroenterol. Hepatol. 2007, 22, 1791-1799.

34. Koca, S.S.; Ozgen, M.; Aydin, S.; Dag, S.; Evren, B.; Isik, A. Ghrelin and obestatin levels in rheumatoid arthritis. Inflammation 2008, 31, 329-335.

35. Liu, X.; Chen, Z.; Mao, N.; Xie, Y. The protective of hydrogen on stress-induced gastric ulceration. Int. Immunopharmacol. 2012, 13, 197-203. 